\title{
Políticas culturales en acto. Teatro comunitario argentino: entre el Estado y la autogestión
}

\section{Clarisa Inés Fernández}

IDIHCS. Instituto de Investigación en Humanidades y Ciencias Sociales (Conicet-UNLP) clarisainesfernandez@gmail.com

\section{Resumen}

El presente artículo se propone indagar en las tensiones del trinomio Estado, cultura y organizaciones comunitarias, a partir del análisis de las políticas culturales, su gestión e implementación por parte de grupos de teatro comunitario argentino durante los años 1983-2015. Los objetivos que invoca este trabajo se orientan a poder identificar los distintos paradigmas que sustentan las políticas culturales y a rastrear momentos de apertura o clausura de espacios de participación comunitaria en el ámbito de la cultura. En última instancia, ello nos hablará de los modos en que el Estado se ve involucrado en el desarrollo de la vida cultural de estas comunidades, y de las estrategias que estas comunidades despliegan para potenciar las propuestas estatales, disputarlas y/o modificarlas. Trabajaremos con dos casos: el grupo Catalinas Sur y el Teatro Comunitario de Rivadavia, lo que nos permitirá también visualizar diferencias en metodologías de construcción de poder en ámbitos urbanos y rurales.

Palabras clave: políticas culturales; Estado; teatro comunitario argentino

\section{Abstract. Cultural policies in action. Argentinean community theater: Between the state and self-management}

This article aims to investigate the tensions arising in the triad of state, culture and community organizations based on the analysis of cultural policies and their management and implementation by Argentinean community theater groups during the period 1983-2015. The objectives are to identify the different paradigms that sustain cultural policies and to trace moments of opening or closure in community participation in the field of culture. Ultimately, this will tell us about the ways in which the state is involved in the development of the cultural life of these communities, and the strategies that they develop in order to promote or dispute the state proposals. The cases of Catalinas Sur and Teatro Comunitario de Rivadavia are analyzed, which allow us to visualize differences in power-building methods in urban and rural areas.

Keywords: cultural policies; state; Argentinean community theater 


\begin{tabular}{|c|c|}
\hline \multicolumn{2}{|c|}{ Sumario } \\
\hline 1. Introducción & 5. ¿Por qué el teatro comunitario \\
\hline \multirow{2}{*}{$\begin{array}{r}\text { 2. La centralidad de la cultura } \\
\text { en Latinoamérica }\end{array}$} & argentino? \\
\hline & 6. Aclaraciones metodológicas \\
\hline \multirow{2}{*}{$\begin{array}{l}\text { 3. Estado, política y cultura: } \\
\text { algunas coordenadas teóricas }\end{array}$} & 7. Análisis comparativo de casos \\
\hline & 8. Reflexiones finales \\
\hline $\begin{array}{r}\text { Las políticas culturales en Argentina: } \\
\text { una reconstrucción histórica }\end{array}$ & Referencias bibliográficas \\
\hline
\end{tabular}

\section{Introducción}

El presente artículo se propone indagar en las tensiones del trinomio Estado, cultura y organizaciones comunitarias, a partir del análisis de las políticas culturales, su gestión e implementación por parte de grupos de teatro comunitario argentino durante los años 1983-2015. Los objetivos que invoca este trabajo se orientan a poder identificar los distintos paradigmas que sustentan las políticas culturales y a rastrear momentos de apertura o clausura de espacios de participación comunitaria en el ámbito de la cultura. En última instancia, ello nos hablará de los modos en que el Estado se ve involucrado en el desarrollo de la vida cultural de estas comunidades, y de las estrategias que estas comunidades despliegan para potenciar las propuestas estatales, disputarlas y/o modificarlas. Trabajaremos con dos casos: el grupo Catalinas Sur y el Teatro Comunitario de Rivadavia, lo que nos permitirá también visualizar diferencias en metodologías de construcción de poder en ámbitos urbanos y rurales.

En principio deberíamos preguntarnos por qué es importante tomar la cultura como eje para nuestro trabajo. La relevancia de la cultura en Latinoamérica y el resto del mundo proviene de varios frentes, por su vinculación con la economía, con el desarrollo y con la política. Allí se destaca el modo en que la cultura puede convertirse en un elemento clave en estos ámbitos, ubicando las políticas culturales en el epicentro de reflexiones que las articulan con el Estado y la economía. Sin embargo, antes de abordar estos argumentos, es necesario hacerse una serie de preguntas previas: ¿qué entendemos por políticas culturales?, ¿cuál es el papel del Estado en el desarrollo de la cultura?, ¿cuáles son las particularidades que revisten estas relaciones en el caso de Argentina? En las siguientes páginas intentaremos ensayar algunas respuestas, y asentar una serie de certezas que nos permitan luego abordar los casos específicos de estudio.

\section{La centralidad de la cultura en Latinoamérica}

Para comprender la centralidad que ha adquirido el tema de la cultura tanto a nivel mundial como en Latinoamérica, comenzamos por dar cuenta del modo en que la cultura se instaló como problema central en las agendas de los organismos mundiales. 
Infantino (2008: 40) apunta que la UNESCO, a través de las distintas convenciones (1989, 1995, 2001, 2003), fue estableciendo la necesidad de crear políticas relativas a la cultura con el fin de defender la diversidad cultural en el contexto de globalización, y como herramienta para paliar crisis socioeconómicas estructurales. En el mismo sentido, Rubim (2006:8) plantea que la cultura pasó a tener un lugar central en la agenda mundial en la Convención de la UNESCO de 2005. Así, Estados Unidos y Francia hablaron de «gerentes o administradores culturales», España de «animadores o promotores culturales» y América Latina de "promotores o trabajadores culturales». Bayardo (2008:11) arroja luz sobre esta cuestión, a través de una historización por medio de la cual reconstruye los modos en que los organismos internacionales promovieron la cultura como eje fundamental del desarrollo, e identifica los vaivenes políticos que impregnaron estas lógicas ${ }^{1}$. De ello se desprende, según el autor, la necesidad de «trascender el carácter corporativo y fragmentario del sector cultural».

En este marco, la cultura como epicentro de políticas internacionales se presenta como una dimensión que pasa a movilizar poderosas fuerzas económicas y políticas, y Garretón (2008) llega a preguntarse si no será a través de la cultura que América Latina pueda construir un espacio de unidad cultural latinoamericana. En esa perspectiva, Mejía Arango (2009) reconstruye la evolución de las políticas culturales en América Latina, identificando profundos cambios en el continente y los modos en que estos afectaron a las políticas culturales. Allí es donde se hace más visible la articulación contemporánea entre cultura, política y economía, que presenta dilemas del cruce entre lo social y lo cultural, generando un diálogo más cercano con la sociedad civil (Camarotti, 2014). En esa línea, el proceso de autonomización de la esfera cultural en América Latina se vio afectado a partir del momento en el que el Estado asumió un rol central en la organización y gestión del circuito de producción, difusión y consumo cultural, el cual fue cambiando con el paso de los años. Rubim (2006) resalta que durante los años 70 el Estado desarrolló políticas vinculadas a la preservación y conservación del patrimonio histórico y el fomento de la cultura de elite, mientras que en los 80 algunos proyectos políticos de carácter nacionalista entraron en crisis y se impuso un nuevo orden globalizado. Es allí donde se habría producido un cambio radical en las esferas tradicionales de operación del Estado, y habrían entrado en escena el mercado y la sociedad civil, disputando protagonismo en el ámbito cultural. Siguiendo esta línea, los 90 se caracterizaron por la dogmatización neoliberal de los mecanismos del mercado, el impacto de las nuevas tecnologías, la masificación del consumo cultural y la expansión de los grandes aparatos culturales. Ya en el siglo XXI, con una mayor aceptación del fenómeno de la globalización, adquirió

1. Bayardo (2008) cita el Informe Mc Bride, que fue presentado en 1980 en la UNESCO, el cual proponía un nuevo orden mundial de la información y la comunicación, basado en la desconolonización, la desmonopolización y la democratización de estas esferas. El autor destaca que el informe se murió antes de ver la luz, porque las agendas internacionales de los países centrales se opusieron a esta propuesta. Estados Unidos y Reino Unido abandonaron la UNESCO y esta quedó debilitada. 
centralidad la diversidad cultural en el marco de la hibridación de identidades, la interculturalidad y la revalorización de la política (Garretón, 2008).

Es en este punto donde el trinomio Estado, cultura y organizaciones comunitarias comienza a adquirir densidad y complejidad, porque la política y la economía lo atraviesan y nos permiten visualizar otras dimensiones ineludibles de analizar, como las industrias culturales y el consumo cultural, el Estado como garante de derechos en el acceso a la cultura, el rol de las empresas, las recientes discusiones sobre la gestión cultural, y los colectivos comunitarios como organizaciones de la sociedad civil que inciden en el desarrollo de la cultura a través de su lucha por el cumplimiento de derechos ciudadanos.

Podemos situar el inicio de nuestra discusión en las transformaciones operadas con el advenimiento de la modernidad, donde la cultura comienza a constituirse como un campo particular. Si bien no retomaremos las extensas referencias existentes en torno a las distintas visiones sobre la cultura que se sucedieron, nos interesa dar cuenta del modo en que esta está necesariamente articulada con la política y la economía. Cuando hablamos de una mirada económica sobre la cultura surgen dos líneas de fuga que nos interesa ahondar: por un lado, la cultura como vector potencial del desarrollo, y por el otro, la dimensión mercantil de la cultura. Entre estas dos líneas Bayardo se pregunta: «PPor qué financiar al sector cultural y cómo?» (2002: 1).

Partimos de entender que existe un vínculo ineludible entre cultura, política y economía (mercado). En este marco asistimos a una culturalización de la economía — porque la economía apela cada vez más a elementos simbólicos e ingenierías culturales - y una economización de la cultura - porque la cultura se incorpora cada vez más al mercado (ídem)—. Respecto a esta cuestión, la historiadora del arte Raymonde Moulin (1986) analiza el mercado internacional del arte contemporáneo, el cual se sitúa en una compleja interacción con las instituciones culturales, donde operan las evaluaciones estéticas y los reconocimientos sociales. La interacción entre mercado y campo cultural fija el valor de las obras y artistas - valores artísticos-. En el campo artístico se producen y se revisan las evaluaciones estéticas y en el mercado se realizan las transacciones y se elaboran los precios. Si bien cada uno de ellos tiene su propio sistema para establecer el valor, ambos mantienen una relación de estrecha interdependencia. Si bien nuestro objeto de análisis no son las obras que circulan en espacios artísticos consagrados (como galerías, museos, entre otras), no podemos dejar de tener en cuenta esta dimensión de la mercantilización del arte, donde juegan un rol fundamental las instituciones culturales en articulación con el mercado internacional.

Además, tienen roles cruciales en el financiamiento de la cultura tanto los grandes bancos internacionales - como el Banco Mundial, el Fondo Monetario Internacional y el Banco Interamericano de Desarrollo, que además de promover programas intervienen en las políticas culturales de los Estadoscomo las empresas, las cuales se convirtieron en agentes de la cultura al articular y generar alianzas con distintos sectores estatales. 
El Régimen de Promoción Cultural (Ley de Mecenazgo) que rige en la Ciudad de Buenos Aires ${ }^{2}$ desde el año 2006 es una de las legislaciones a nivel cultural más controvertidas. Propone que los proyectos culturales puedan conseguir apoyo económico de las empresas a cambio de que estas reduzcan sus contribuciones del impuesto de ingresos brutos. La idea de mecenazgo promueve beneficios económicos en las grandes empresas, derivándoles un rol de patrocinio que estimula finalmente la labor de los colectivos artísticos de mayor trayectoria y de expresiones de la «alta cultura», aquellos que las empresas deciden apoyar por interés empresarial y corporativo. Tanto en Brasil como en Argentina, este modelo de financiamiento ha beneficiado a los grupos artísticos de mayor reconocimiento (Lima, 2010).

El financiamiento de la cultura se convierte así en una cuestión imprescindible de abordar para pensar en políticas públicas culturales, pues entendemos que, igual que en todas las áreas de la vida social, desarrollar y mejorar la vida cultural de una comunidad requiere recursos. Consideramos que el auge de las industrias culturales y la complejización de los procesos de distribución y comercialización de bienes culturales ${ }^{3}$ no necesariamente conllevan una «inversión» en el desarrollo cultural de una comunidad, ya que, para que esto suceda, debe recuperarse la dimensión política de la cultura, orientada en un proceso de desarrollo con justicia social (Porto, 2004), o, como dice Grimson (2014), debe ponerse el foco en el eje de la «justicia cultural». De esta forma, emparentamos ambas ideas del autor - justicia cultural y desarrollo cultural- porque ambas implican un «proceso de incrementación de la autonomía y la libertad de los seres humanos, proceso que requiere a la vez bases materiales y simbólicas» (Grimson, 2014: 11).

\section{Estado, política y cultura: algunas coordenadas teóricas}

Para recuperar la dimensión política de la cultura y comprender sus implicancias concretas en el ámbito de lo social, resulta ineludible preguntarse por los modos en que el Estado lleva adelante políticas culturales. Esto implica indagar en las lógicas que se despliegan entre el aparato estatal propiamente dicho, los agentes involucrados, las organizaciones comunitarias y los actores privados. El Estado interviene en la cultura porque «está afectando los sistemas de producción, circulación, distribución y reconocimiento del sentido» (Margulis et al., 2014: 11). En ese sentido, concebimos el Estado como un espacio que no está conformado solo por instituciones, sino también por ideas y una correlación de fuerzas políticas, «lo que hace que se constituya como campo de disputa política por la reproducción o transformación del orden social»

2. Actualmente el gobierno de Mauricio Macri ha impulsado con mayor énfasis las gestiones para que la Ley de Mecenazgo pueda tener alcance nacional.

3. Hablamos de la rentabilidad generada por la diversificación de la industria de la información, la comunicación y el entretenimiento, y el patrimonio, la moda, el diseño, el turismo, etcétera (Bayardo, 2005). 
(Barbosa Lima, 2014: 120). Desde esta perspectiva nos interesará comprender cómo esa disputa se da a nivel interno, analizando el Estado desde un punto de vista contextual a partir de la dinámica de sus propias estructuras.

A través de las políticas culturales implementadas por el Estado, puede influirse concretamente en el acceso a bienes culturales, a espacios de expresión, a reivindicaciones culturales y sobre parámetros socioeconómicos. Si la cultura es entendida como un derecho, el Estado debería garantizar el acceso a ella para todos los ciudadanos. Sin embargo, un Estado en crisis «es asumido como incapaz por sí solo de hacerse cargo de 'la cultura' y se genera un espacio propicio para la proliferación de diversas organizaciones en la sociedad civil» (Infantino, 2008: 40). Es aquí donde las distintas instituciones y grupos de la sociedad civil tejen una red de acción que suple en muchos casos la responsabilidad estatal en el cumplimiento del derecho al acceso a la cultura. Pero suponer que estas organizaciones pueden equipararse a una tarea estatal es una trampa peligrosa: en primer lugar, no cuentan con los mismos recursos ni el mismo poder (Raggio, 1997); en segundo lugar, la cultura como escenario de disputa política es un terreno complejo cuyas bases aún se encuentran empantanadas con estereotipos e imaginarios vinculados a la «alta cultura», donde no hay una igualdad en la valoración y significación de las prácticas culturales, y los grupos artísticos subalternos generalmente son los perjudicados.

Bayardo plantea:

A diferencia de los derechos civiles y políticos, donde se reclama que el Estado no intervenga si no ante una violación, en el caso de los derechos, económicos, sociales y culturales se entiende que estos no pueden ser alcanzados si no mediante políticas y prácticas activas que aseguren su implementación. De ahí que desde mediados del siglo XX las políticas públicas culturales no son una opción, sino una obligación del Estado para con la ciudadanía (2005a: 1).

Los estudios sobre políticas culturales se han multiplicado en el transcurso de los últimos años, tanto en América Latina como en Europa (Orozco, 2007). Se han realizado investigaciones en torno a la evolución de las políticas culturales (Mejía Arango, 2009; Nivón, 2011), en torno al vínculo entre políticas culturales y participación ciudadana (Escobar et al., 2001; Ferreño, 2014), sobre la incidencia de las políticas culturales en las desigualdades económicas y simbólicas (Grimson, 2014), sobre distintos aspectos que abordan procesos de institucionalización de la cultura (Tovar, 1994; Crespo, 2003), estudios de caso de implementación de políticas culturales (Bonfil, 2002; Nivón, 2004, 2006), y políticas gubernamentales concretas (López, 2001). Encontramos también reconstrucciones de la trayectoria conceptual del término, clasificaciones y discusiones en torno a los paradigmas que las sustentan (García Canclini, 1987; Brunner, 1987; Ochoa, 2002; Bayardo, 2008a, 2008b; Maccioni, 2002; Mato, 2002; Wortman, 2002, 2005; Logiódice, 2012), su utilización en el contexto latinoamericano y las diferencias con las cultural politics europeas (Yúdice, 2002). 
Concebimos las políticas culturales como terreno de luchas por el poder en donde se dan mediaciones entre lo cultural y lo político (Logiódice, 2012), espacios donde se desarrollan conflictos, coaliciones, movilización de recursos, grados relativos de autonomía y poder (Oszlak y O'Donnell, 2007), con capacidad de habilitar o clausurar demandas por derechos colectivos. Según Grimson (2014), las políticas culturales comprenden lo cultural como constitutivo de la ciudadanía y los derechos culturales, tan relevantes como los económicos, sociales y políticos, porque funcionan como dispositivos de las relaciones de fuerza sociales vigentes en un contexto determinado (Ferreño, 2014). A su vez, las representaciones del mundo y de lo social ofrecidas por las políticas culturales actúan como mediadores en los modos de ver a los «otros» y de verse a sí mismos de los diversos grupos humanos, y además ejercen influencia — con diversos grados - en las capacidades de interactuar y de tomar decisiones acerca de su presente y futuro.

Si consideramos, junto con Escobar, Álvarez y Dagnino (2001), que las prácticas no se pueden aislar de los significados que conllevan, la política cultural es «un espacio donde se determina quiénes tienen el poder de precisar los significados y a su vez influir en la aceptación o el cuestionamiento de las relaciones de poder imperantes» (Ferreño, 2014: 111), a la vez que es un terreno de ejercicio de la cultura, una de las dimensiones de la ciudadanía y de la vida social en general. Las políticas culturales están sustentadas por determinados paradigmas culturales, que conciben la cultura de un modo particular ${ }^{4}$. A través de estos paradigmas, se pueden explorar las políticas culturales en relación con el Estado, pero sin perder de vista las interacciones con otros agentes como las empresas y los grupos comunitarios, los cuales obran, generalmente, con relación a las intervenciones del Estado, sus infraestructuras, sus medios de financiamiento, sus regulaciones y sus arbitrajes de los conflictos, sea por acción o por omisión.

En esta línea, cabe preguntarnos, entonces, cuál es el sustento de las políticas culturales que se han implementado en Argentina, de qué manera se vinculan con los proyectos políticos y gestiones de turno, y cómo podemos caracterizar el momento actual del país, en relación con el ámbito cultural.

\section{Las políticas culturales en Argentina: una reconstrucción histórica}

En Argentina, el sector cultural estuvo tradicionalmente apoyado por la Administración pública, y las dos instituciones que inauguraron espacios nacionales de financiación al sector cultural fueron el Fondo Nacional de las Artes, creado en 1958, y la Secretaría de Cultura de la Nación, nacida en 1954 (Bayardo, 2005b). Sin embargo, si quisiéramos hacer una reconstrucción de las políticas culturales que tuvieron lugar en Argentina, no podemos dejar

4. En un ya clásico trabajo sobre políticas culturales, García Canclini (1987) identifica seis paradigmas culturales: mecenazgo liberal, tradicionalismo patrimonialista, estatismo populista, privatización neoconservadora, democratización cultural y democracia participativa. 
Tabla 1. Cultura y políticas culturales

\begin{tabular}{|c|c|c|}
\hline Periodos históricos & Tendencias internacionales & Contexto local \\
\hline Años 50-60 & $\begin{array}{l}\text { - Desde el fin de la Segunda Guerra Mundial, } \\
\text { las políticas culturales estuvieron asociadas } \\
\text { a proyectos de liberación o afirmación } \\
\text { nacional (Nivón, 2011; Mejía Arango, 2009) } \\
\text { — Políticas culturales que buscaban exaltar la } \\
\text { «expresión auténtica y legítima de lo nacio- } \\
\text { nal». Los derechos culturales estaban vincu- } \\
\text { lados a la idea de nación (Bayardo, 2008) }\end{array}$ & $\begin{array}{l}\text { - Creación de organismos nacionales } \\
\text { culturales: Fondo Nacional de las Artes y } \\
\text { Secretaría de Cultura de la Nación, según } \\
\text { los modelos de políticas culturales francés } \\
\text { y anglosajón (Bayardo, 2005b) } \\
\text { - Creación del Instituto Nacional de Cinema- } \\
\text { tografía (1957) }\end{array}$ \\
\hline Años 70 & & $\begin{array}{l}\text { — Paradigma de acción cultural llamado } \\
\text { «tradicionalismo patrimonialista», que } \\
\text { busca conservar el patrimonio folklórico } \\
\text { sobre el «ser nacional» (Pallini, 2008) } \\
\text { — Creación del Comité Federal de Radiodifu- } \\
\text { sión (Comfer) } \\
\text { — 1980: Ley } 22.285 \text { de Radiodifusión }\end{array}$ \\
\hline Años 80 & $\begin{array}{l}\text { - Expansión conceptual y programática de la } \\
\text { cultura hacia las industrias culturales y los } \\
\text { medios de comunicación. Esto no implicó } \\
\text { una democratización de la cultura (Bayardo, } \\
\text { 2008) }\end{array}$ & $\begin{array}{l}\text { — Durante el gobierno de Raúl Alfonsín se } \\
\text { buscó mayor intervención del Estado en } \\
\text { la formulación de políticas culturales, pero } \\
\text { estas no fueron planificadas } \\
\text { — Iniciativas para fomentar la participación } \\
\text { ciudadana en el ámbito cultural } \\
\text { — Democratizar y diversificar el consumo } \\
\text { cultural (Winocur, 1993) } \\
\text { — Plan Nacional de Cultura (1984-1989) } \\
\text { — Programa de democratización de la cultura } \\
\text { (Prondec) }\end{array}$ \\
\hline Años 90 & $\begin{array}{l}\text { — Irrupción de la globalización } \\
\text { — Pérdida de la centralidad de la política pos- } \\
\text { transiciones democráticas } \\
\text { — Explosión identitaria } \\
\text { — Masificación cultural } \\
\text { — Primer impacto de las nuevas tecnologías } \\
\text { de la comunicación (Garretón, 2008) } \\
\text { — Noción antropológica de cultura. Inclusión } \\
\text { de otras actividades en la esfera de la cultu- } \\
\text { ra: moda, diseño, patrimonio, gastronomía, } \\
\text { turismo (Bayardo, 2008a) }\end{array}$ & $\begin{array}{l}\text { - Disminución del financiamiento público } \\
\text { a la cultura y aumento de la rentabilidad } \\
\text { sobre la misma área } \\
\text { — Privatización neoconservadora } \\
\text { — Estado visto como ineficiente } \\
\text { — 1994: Ley de Cine } \\
\text { — 1997: Ley de Teatro }\end{array}$ \\
\hline Año 2000 & $\begin{array}{l}\text { — Mayor aceptación de la globalización } \\
\text { — Nuevo sentido de la diversidad cultural } \\
\text { — Unidad nacional bajo el concepto de hibri- } \\
\text { dación de identidades, revalorización de la } \\
\text { política } \\
\text { — Búsqueda de nuevos sentidos para las TIC } \\
\text { (Garretón, 2008) } \\
\text { — Centralidad de las políticas culturales en la } \\
\text { agenda mundial (Bayardo, 2008) }\end{array}$ & $\begin{array}{l}\text { - Creación del Sinca (2006) } \\
\text { — Creación del Consejo Federal de Cultura } \\
\text { (2008) } \\
\text { — Aprobación de la Ley de Servicios de Comu- } \\
\text { nicación Audiovisual (Ley N² 26.522) (2009) } \\
\text { — Creación del AFSCA (2009) } \\
\text { — Creación del Ministerio de Cultura de la } \\
\text { Nación (2014) } \\
\text { — Inicio del programa Puntos de Cultura (2011) }\end{array}$ \\
\hline
\end{tabular}


de mencionar que estas estuvieron enmarcadas en las tendencias impulsadas por los organismos internacionales. Más allá de las referencias que hemos hecho a las convenciones de la UNESCO como instancias clave en la orientación de estas políticas, resulta esclarecedor poder articular las tendencias internacionales con los contextos históricos locales.

A partir de este cuadro, podemos ver que históricamente existió y existe una fuerte vinculación entre las tendencias que impulsan los organismos internacionales y las organizaciones mundiales en materia de cultura, con los contextos políticos y sociales, y las coyunturas locales de cada país. En el caso de Argentina, después de atravesar la década del 90, el nuevo siglo trajo nuevos dilemas en materia cultural. Si pensamos cómo es el escenario actual de las políticas culturales en Argentina, debemos comenzar por destacar que a pesar de que tanto en América Latina como en Argentina la acción de las políticas culturales más visible fue la del Estado (Ochoa Gautier, 2002), otros actores de la sociedad civil, el mercado, los actores comunitarios, las empresas y las ONG, entre otros, juegan un papel protagónico en la cadena de planificación, gestión e implementación de las políticas culturales.

Martín Zamorano (2016) analiza la transformación de las políticas culturales en Argentina durante los años 2003-2013, donde identifica una continuidad con relación a los elementos que históricamente caracterizaron este ámbito: la falta de soporte presupuestario, la concentración de recursos en la Ciudad Autónoma de Buenos Aires y la inexistencia de una institucionalidad fuerte. Además, señala que las producciones fueron limitadas respecto al conjunto de las políticas sociales, lo que impidió dotar de jerarquía las instituciones culturales. Sin embargo, coincidimos con este autor en destacar que se hicieron avances con relación a la inclusión digital y el campo de la cultura popular, ampliando la definición de cultura desde la que se parte en relación con el Estado, y generando una serie de estructuras administrativas que permitieron la expansión de la actividad cultural y un replanteo más profundo sobre la importancia de la misma como espacio de disputa de derechos. En esa perspectiva, señalamos la creación del Ministerio de Cultura (2014), la aprobación de la Ley 26.522 de Servicios de Comunicación Audiovisual y la creación de la Autoridad Federal de Servicios del organismo de Comunicación Audiovisual (AFSCA), en el año 2009. Dentro de esta línea, el politólogo José Nun —secretario de Cultura del año 2004 al 2009- llevó adelante una política basada en la idea de la democratización cultural. Durante su gestión, en el año 2006, se creó el Sistema de Información Cultura de la Argentina (Sinca), cuyo objetivo era recopilar información para la realización de estadísticas que distinga los diversos perfiles de consumo según las regiones del país. Este marco nos permite dar cuenta de un contexto político específico desde donde se pensaron e implementaron las políticas culturales en este periodo, el cual cambió radicalmente en diciembre de 2015, con la asunción de la nueva gestión política, la cual excede este escrito.

Tanto Esteban (2013) como Infantino (2008) destacan que las políticas culturales locales empezaron a incluir cada vez más objetivos sociales en sus 
definiciones, los cuales pretenden alcanzarse a través de programas y acciones comunitarias. Sin embargo, a pesar de los objetivos enunciados tanto en las convenciones de la UNESCO como en los discursos locales, de la centralidad que ha adquirido la cultura con relación al desarrollo y la igualdad, «la institucionalidad cultural se ve debilitada económica, conceptual y políticamente» (Mejía Arango en Lima, 2010: 10). Esta debilidad puede venir dada por varias cuestiones. Al respecto, Bayardo (2005b) apunta que el marco institucional del sector y de la Administración pública en general no contribuye al desarrollo de formas de evaluación y diseño de políticas culturales. La información oficial no se recopila ni sistematiza. Además, el autor señala el hecho de que los gobiernos aprovechan en muchos casos las propuestas de la sociedad civil y el financiamiento internacional, pero no llegan a consolidar políticas a largo plazo y de bien común.

Pallini (2008), en un estudio realizado sobre el rol del Estado en las políticas culturales, en el caso del Teatro Municipal General de San Martín, afirma que hay una ausencia de lineamientos explícitos sobre cuál debe ser la tarea del Estado en materia cultural, por lo cual solo se construyen políticas de corto plazo que responden a situaciones coyunturales.

Hay algunos elementos inherentes a la práctica de la política estatal que inciden en la constitución de esta dinámica, en perjuicio de la planificación y el desarrollo de políticas culturales de largo alcance. Entre ellas, podemos señalar que la cultura es uno de los ámbitos que el Estado más ha tercerizado, probablemente porque es un terreno donde aún no existe un consenso acerca de cuáles son las necesidades culturales y los derechos que el Estado debe garantizar (Infantino, 2008). La misma autora destaca algo que en principio puede resultar menor, pero que en la práctica se convierte en una de las dificultades más concretas para los colectivos artísticos que solicitan financiamiento: las lógicas burocráticas, la articulación y la superposición de políticas, que muchas veces se ven profundizadas por los cambios de gestión. En ese sentido, encontramos que las modalidades que el Estado actualmente prioriza como vías de acceso al financiamiento de las actividades culturales son los programas, subsidios, becas, créditos y premios. Estas se sustentan en una serie de legislaciones que implican la necesidad de saberes y competencias en el ámbito administrativo —-llenado de formulario, presentación de documentación, rendiciones, etcétera—. Estas instancias terminan creando un filtro, por el cual solo pasan aquellos grupos que poseen personal especializado en estas cuestiones.

Otro debate que se abre en torno a la acción de las políticas culturales es el de la llamada gestión cultural. Entendida, según Bayardo (2005a), como una mediación entre los procesos productivos culturales que involucran a distintos agentes, prácticas y racionalidades, la gestión cultural se ha vinculado con la idea del marketing, y una finalidad cortoplacista en las políticas. Si bien no entraremos en este debate aquí, es importante tener en cuenta que la noción de gestión cultural abre un panorama distinto, donde incluso aparecen cada vez más ofertas universitarias, cursos y especializaciones, enfocados en develar los secretos de la gestión de recursos culturales, remarcando 
la idea de que es necesaria una preparación especial para lograr acceder al financiamiento5.

A pesar de estas cuestiones, nos interesa resaltar dos dimensiones que impregnan las dinámicas de las políticas culturales argentinas actuales, y que, a nuestro entender, amplían el espectro de «lo cultural», tanto geográfica como simbólicamente. En primer lugar, destacamos que no todas las políticas culturales implican una planificación y un control por parte del Estado, ya que algunos programas apuntan al financiamiento de prácticas culturales autónomas, donde se priorizan las demandas que provienen de las comunidades, y el Estado decide apoyarlas. En general, estas prácticas culturales suelen desarrollarse independientemente del Estado y pueden funcionar sin el apoyo estatal, pero potencian sus actividades a través de distintas búsquedas de recursos. La segunda dimensión relevante para nuestro estudio se encuentra en la emergencia de una serie de programas y proyectos que actúan fundamentalmente en Latinoamérica, a través de los cuales se financia la actividad artística comunitaria. Dentro de estos programas encontramos el de Cultura Viva Comunitaria, que tiene su origen en un proyecto brasilero surgido en el año 2004, que propone que el $0,1 \%$ del presupuesto nacional se destine a gestionar actividades culturales de diversas organizaciones y agrupaciones sociales que trabajen vinculadas a la comunidad. Argentina presentó el proyecto análogo en el Congreso en el año 2012, y el colectivo Pueblo hace Cultura ${ }^{6}$ ha llevado adelante esta propuesta, a través de la acción mancomunada de más de 90 grupos, radios, bibliotecas y diversas instituciones de todo el país.

Otra propuesta de este tipo la encontramos en el proyecto Iberescena, creado en el año 2006 en el marco de la Cumbre Iberoamericana de Jefes de Estado y de Gobierno, que tuvo lugar en Montevideo (Uruguay). Los objetivos más importantes de este proyecto se orientan al fomento, el intercambio y la integración de la actividad de las artes escénicas latinoamericanas. Este fondo está apoyado y financiado por 13 países, Argentina, Brasil, Colombia, Chile, Costa Rica, Ecuador, El Salvador, España, México, Panamá, Paraguay, Perú y Uruguay, y por la Secretaria General Iberoamericana (Segib). Ambas propuestas resultan interesantes a la hora de pensar los modos en que las políticas culturales se planifican, negocian y ejecutan en diálogo con las organizaciones de la sociedad civil, principalmente con colectivos artísticos comunitarios, sobre las cuales nos detendremos en el próximo apartado.

5. Si bien nuestro trabajo no retoma la vasta literatura del campo de la gestión cultural, podemos referenciar una serie de lecturas que podrían aportar a la interpretación de nuestro objeto desde otras miradas y a partir de otros territorios: Robert Hewison (2014), Cultural Capital: The Rise and Fall of Creative Britain; Rodríguez Morató (2012), El análisis de la politica cultural en perspectiva sociológica. Claves introductorias al estudio del caso español; Joaquim Rius Ulldemolins, Arturo Rodríguez Morató y Santi Martínez Illa (2012), El sistema de la politica cultural en Cataluña: un proceso inacabado de articulación y racionalización, entre otros.

6. Es un colectivo de organizaciones sociales, culturales, medios de comunicación populares y fuerzas políticas que se unieron en apoyo a la cultura comunitaria. Ver: http://www. pueblohacecultura.org.ar/ 
Ahora bien, para finalizar, consideramos relevante volver a una de las cuestiones iniciales que nos convocan: si creemos que las políticas culturales comprenden lo cultural como constitutivo de la ciudadanía, con capacidad de generar ampliación de los derechos, tanto culturales como sociales, interviniendo en la correlación de fuerzas entre los poderes con vistas a reducir las desigualdades (Camarotti, 2014) y con capacidad de intervención en los distintos planos de la vida social y en las estructuras de significación que sustentan las formas de percibir, apreciar, relacionarse y actuar (Margulis et al., 2014), debemos orientar la mirada hacia las experiencias concretas, donde los grupos artísticos y las organizaciones de la sociedad civil establecen lazos, disputas, negociaciones e intercambios constantes, tanto con los distintos estamentos del Estado como con ONG, empresas, instituciones y con otros grupos. En ese marco se vuelve necesario indagar las complejidades de las políticas culturales como espacios de disputa de poder, con todas sus luces y sombras, en las trayectorias específicas que se tejen con los avatares históricos y los contextos políticos. Aventurándonos en esa empresa, en el siguiente apartado analizaremos estas cuestiones en dos casos particulares: el grupo de teatro comunitario Catalinas Sur y el Teatro Comunitario de Rivadavia.

\section{5. ¿Por qué el teatro comunitario argentino?}

Interpelamos al teatro comunitario argentino como práctica artística y política que dialoga constantemente con el Estado, disputando recursos y estableciendo sus propias «reglas del juego» y mirada sobre la cultura. Este tipo de teatro tiene sus particularidades. Se trata de un teatro producido por y para la comunidad de un territorio determinado (barrio, ciudad, pueblo), que trabaja exclusivamente con la memoria de los vecinos y la identidad local, buscando relatar las historias propias de ese territorio (Bidegain, 2007). Los integrantes de los grupos son vecinos y vecinas de ese lugar, no profesionales del teatro, con diversidades en cuanto a profesiones, pensamientos y edades. Los procesos de creación de las obras se convierten en un modo de reflexionar sobre la propia historia, elaborar interpretaciones del pasado a la luz del presente, y con una idea de futuro. Esta construcción deviene en un ejercicio que, en algunos casos, se erige como práctica crítica en torno a la realidad social de la comunidad y sus problemáticas. Si bien cada grupo alcanza diferentes niveles de profundidad en el proceso reflexivo, el modus operandi de creación artística, y las estrategias organizativas de autogestión de los vecinos promueven nuevos espacios de sociabilidad, signados por códigos específicos de la práctica teatral. Elementos pertenecientes al ámbito privado se vuelcan al espacio público, y ciertas prácticas cotidianas vinculadas a la familia se reproducen entre los miembros del grupo, abriendo canales de interacción social intergeneracional y de índole heterogénea (Fernández, 2012).

El espacio social que inaugura el teatro comunitario permite la reunión, el encuentro, el juego y la interacción entre personas de diversas religiones, ideas políticas, condición social, económica y cultural. El juego como dispositivo de 
cohesión construye vínculos que rompen con prejuicios e imaginarios construidos de antemano, y genera una desnaturalización de la anonimia. Dentro de la gran heterogeneidad de grupos que existen en el país ${ }^{7}$, hay diferencias notables entre grupos urbanos/ rurales, de zonas marginales y zonas céntricas de la ciudad, de trayectoria y elecciones estéticas. Desde el grupo fundador, Catalinas Sur (barrio La Boca), que ya lleva 34 años de existencia y reconocimiento a nivel internacional, pasando por grupos rurales recién formados, la diversidad de los mismos da cuenta de la heterogeneidad de propuestas que este fenómeno incluye. Estas diferencias a nivel decisional abarcan también elecciones vinculadas al nexo que los grupos generan con las comunidades locales, la intervención concreta en el territorio, y el tipo de relato que se construye en el producto teatral. La divergencia en la mirada sobre el pasado (mitificada, idealizada o crítica), la denuncia de problemáticas presentes y la idea de futuro que se presenta establecen diferencias sustanciales en torno a la práctica teatral.

En este sentido, el teatro comunitario ha sido canal de expresión y reclamo por derechos incumplidos en diversas áreas de lo social (trabajo, educación, transporte, igualdad de género) ${ }^{8}$, lo que implica un posicionamiento de la actividad como dispositivo válido en el ejercicio de la ciudadanía. Desde esta perspectiva, el lenguaje artístico posee elementos que pueden potenciar este tipo de reclamos. Por un lado, el juego que se despliega en la escena, los discursos construidos desde la dramaturgia y la utilización de espacios no convencionales permiten decir cosas de otra manera, apelando a la retórica y sus figuras, que delinean modos de decir no confrontativas, desde el humor - la sátira, la ironía, la ridiculización, etcétera- (Fernández, 2015).

Si bien no podemos generalizar con relación al grado de desarrollo que las estrategias de los grupos han alcanzado en materia de gestión, consideramos que el hecho de poder dar cuenta de los procesos de institucionalización y vinculación política de los grupos de la Red Nacional de Teatro Comunitario9 con otros actores (fundamentalmente el Estado) puede ayudarnos a visibilizar la injerencia que los mismos han tenido en el surgimiento e impulso de legislaciones culturales que disputen sentidos en torno a la cultura y el arte, y amplíen el abanico de derechos en el acceso a los bienes culturales. En ese sentido, diversos autores han abordado la capacidad transformadora del teatro comunitario, ya sea en una dimensión social general (Bidegain, 2007) como en los procesos de memoria que se desarrollan en las instancias de creación colectiva (Fernández, 2013), en el espacio público (Proaño Gómez, 2007), con relación a la filosofía y la política (Proaño Gómez, 2013), entre otros. Estos procesos de cambio atraviesan, según los autores, la dimensión subjetiva de la práctica, generando nuevas condiciones de autopercepción en los vecinos, fomentando la recupe-

7. En la actualidad existen alrededor de 50 grupos en todo el país.

8. Así lo registramos en el caso del Teatro Comunitario de Rivadavia en nuestra investigación doctoral (2015).

9. A partir del año 2002 los grupos de teatro comunitario de Argentina conformaron una red nacional a través de la cual se transmiten experiencias, saberes, y se comparten posibles soluciones a problemáticas comunes. 
ración de la autoestima, enriqueciendo el acervo cultural, restableciendo los vínculos sociales y creando espacios de sociabilidad que permitan desnaturalizar sentidos y constituir prácticas de intervención concreta en el territorio.

En ese marco, el Estado impulsa en cada una de sus gestiones y en sus estamentos determinados programas culturales, que son reductos de financiación que los grupos de teatro comunitario disputan para gestionar sus actividades. A su vez, los representantes de los grupos establecen estrategias de participación que les permitan incidir, de una u otra manera en la orientación de esas políticas. Esas modalidades de intervención serán articuladas, también, con otras dirigidas a los sectores privados (empresas, fundaciones) a las cuales los grupos recurren en busca de recursos y apoyo. En esa línea trabajaremos, en lo que sigue, con el análisis de los dos casos mencionados: el Teatro Catalinas Sur y el Teatro Comunitario de Rivadavia.

\section{Aclaraciones metodológicas}

En este apartado daremos cuenta de una serie de cuestiones metodológicas que guiaron nuestro trabajo. En principio, los casos analizados a continuación - Grupo Catalinas Sur y Teatro Comunitario de Rivadavia - fueron seleccionados bajo los criterios que estipulaba nuestro trabajo posdoctoral, en el cual nos interesaba explicar las diferencias de diseño, implementación y gestión de políticas culturales en ámbitos urbanos y rurales. En esa línea, el grupo Catalinas Sur, ubicado en el barrio porteño de La Boca de la Ciudad de Buenos Aires, es el grupo de teatro comunitario urbano con mayor trayectoria del país, y ha configurado, a lo largo de sus 34, diversas estrategias de gestión y vínculo con el Estado, en sus diferentes estamentos (municipal, provincial y nacional).

Respecto al Teatro Comunitario de Rivadavia, consideramos que se trata de un caso paradigmático dentro de los grupos de teatro comunitario rural, ya que ha generado, en sus siete años de existencia, una estructura organizativa que nuclea seis pueblos rurales, que articula con instituciones locales, nacionales e internacionales, y cuyo trabajo se ha concretado y ampliado en la conformación de la Cooperativa La Comunitaria. Esta institución se convirtió en una organización social con capacidad de disputa política local (Fernández, 2012, 2015), donde el teatro fue el puntapié inicial para el surgimiento de iniciativas laborales, sociales, vinculadas a los derechos humanos, entre otras.

Hemos trabajado a partir de un diseño de investigación cualitativa (Marradi et al., 2007), donde retomamos un corpus de políticas culturales y reconstruimos los modos en que los dos grupos seleccionados participaron, gestionaron, disputaron y/o implementaron dichas políticas. Podemos distinguir tres momentos articulados que formaron parte de la estrategia metodológica abordada:

a) Elaboración de un corpus de políticas públicas provenientes del Estado en su nivel municipal, provincial y nacional destinadas a organizaciones culturales comunitarias. 
b) Reconstrucción de estrategias de gestión e implementación de dichas políticas por parte del grupo Catalinas Sur y Teatro Comunitario de Rivadavia.

c) Análisis comparativo de las fases anteriores que nos permita identificar distintos modos de construcción de poder y de vinculación con el Estado, agentes intervinientes, tensiones y conflictos.

Para la recolección de datos trabajamos con la indagación de fuentes documentales, archivos y programas de gobierno. Si bien el grupo Catalinas Sur ha recibido apoyo de organismos e instituciones nacionales e internacionales, como también de fundaciones y ONG, focalizaremos nuestro análisis exclusivamente en las políticas culturales estatales promovidas desde 2002 a 2015. Entre ellas encontramos el programa de Cultural en Barrios (Ciudad de Buenos Aires, iniciado en 1984 y vigente), el programa nacional Puntos de Cultura (iniciado en el 2011 y vigente) y el Mecenazgo Cultural del Régimen de Promoción Cultural de la Ciudad de Buenos Aires (iniciado en el 2006 y vigente). El programa latinoamericano de Cultura Viva Comunitaria se ha venido impulsando en Argentina desde el año 2011, estrechamente vinculado con el programa de Puntos de Cultura. Tanto el grupo de Catalinas Sur como el de Rivadavia han participado activamente de este espacio, y sus líderes son referentes militantes y políticos dentro de la Red Nacional de Teatro Comunitario. Como dispositivos de acceso a los datos, utilizaremos, además de los documentos hallados en los archivos digitales de los sitios gubernamentales, las herramientas de estadísticas y datos cuantitativos relevados en Sistema de Información Cultural de la Argentina (Sinca), el sistema de información cultural de la Secretaria de Cultura de la Nación.

Otra técnica utilizada fueron las entrevistas semiestructuradas a los referentes de los grupos ${ }^{10}$, que nos permitieron reconstruir las visiones subjetivas sobre los vínculos y articulaciones tejidas entre ambos. Focalizamos la atención en las estrategias de negociación y gestión, conflictos y tensiones en ese proceso. Los modos de gestión y participación de los grupos en la creación y/o implementación de las políticas culturales fueron relevados mediante técnicas de corte cualitativo. La producción de datos y su análisis se realizaron mediante una estrategia comparativa, que nos permitió dar cuenta de cómo se dio este proceso de articulación de los grupos con el Estado, puntualizando la diferenciación urbano-rural.

\section{Análisis comparativo de casos}

\subsection{Grupo Catalinas Sur}

El grupo de teatro comunitario Catalinas Sur se considera el fundador del teatro comunitario argentino. Surgió en el año 1983, cuando un grupo de

10. Se realizaron entrevistas a la directora del Teatro Comunitario de Rivadavia, a los integrantes de La Comunitaria y al entonces intendente del municipio, durante los años 2010-2014. Respecto del Teatro Catalinas Sur, se entrevistó a su director en el año 2016 y a los integrantes del grupo encargados de la gestión de recursos a través del pedido de subsidios. 
padres nucleados en la Asociación Mutual de la Escuela No 8 Carlos Della Pena del barrio porteño de La Boca realizaban trabajos en el barrio. Después de ser expulsados de la mutual de la escuela por las fuerzas del Gobierno de facto, alquilaron un local y posteriormente se mudaron a uno prestado. Allí dieron varios talleres. En marzo de 1983 se propuso convocar como director a Adhemar Bianchi, uno de los padres de la escuela y teatrista uruguayo con una vasta trayectoria en el mundo del teatro ligada a la militancia política. Ese grupo de teatro recién formado, que adoptó el nombre de Grupo de Teatro al Aire Libre Catalinas Sur, comenzó a trabajar con vecinos a través de la creación colectiva.

En 1993 Catalinas Sur realizó un convenio con la Dirección de Promoción Cultural de la Secretaría de Cultura de la Ciudad de Buenos Aires, de la cual consiguieron el apoyo del programa Cultural en Barrios ${ }^{11}$. Se empezaron a dar talleres de teatro, percusión música, títeres, máscaras, escenografía, vestuario, malabares, zancos, coros, candombe, murga, entre otros. En 1997 se trasladaron a un galpón techado ubicado en el centro del barrio de La Boca, que compraron en 1999 (Bidegain, 2007). Su trayectoria como grupo conformado ya en compañía internacional de teatro es destacable en cuanto a la calidad estética de sus producciones, las estrategias para conseguir recursos y la relación que establecieron con la comunidad. Con 34 años de trayectoria, han recibido innumerables premios, cuentan con el apoyo de fundaciones, organismos nacionales e internacionales y tienen más de 16 espectáculos estrenados.

El grupo Catalinas Sur es un caso paradigmático, ya que, a lo largo de su trayectoria y a pesar de los diversos contextos políticos, logró mantener su actividad a través de la autogestión, y en contacto permanente con distintos estamentos del Estado. Para poder reconstruir y analizar el vínculo que este grupo mantuvo con el poder estatal y los procesos de negociación, disputa y acceso a las políticas culturales, es fundamental entender cómo este concibe a la figura del Estado. Si bien Catalinas Sur no surgió de un programa estatal ni con recursos públicos, a lo largo de su historia estuvo ineludiblemente ligado al poder estatal. En palabras del director:

Nosotros creemos que el Estado debe estar, pero apoyando lo que sale de la comunidad y no dirigiéndolo. (...) Exigimos que esté esa relación, pero que no se nos condicione de ningún sentido. En la relación con el Estado hay algunos temas que tienen que ver con saber cómo se hace la gestión, y que nunca te cuenten como tropa propia (...), nosotros sabemos que no conviene trabajar con un partido ${ }^{12}$.

Tomando la reflexión esbozada por Bianchi, nos encontramos con la idea de que el Estado debe estar presente como garante de derechos culturales. Por otro lado, se vislumbran las tensiones que suelen presentarse en las experiencias

11. Programa creado por la Secretaría de Cultura de la Municipalidad de la Ciudad de Buenos Aires a mediados de 1984, que propone incentivar la participación ciudadana en las actividades culturales.

12. Entrevista a Adhemar Bianchi, noviembre de 2016. 
de movimientos sociales o acciones colectivas en donde el Estado juega un rol importante, aunque no prioritario. En este sentido, creemos relevante remarcar el hecho de que las luchas colectivas que surgen por fuera del Estado deben ser pensadas como una tensión entre ambos (colectivo y Estado) que no pretende resolverse, sino como un proceso de permanente disputa. Como el Estado siempre está presente en el conflicto social, «la concepción de Estado que tenga una organización juega un rol protagónico en las potencialidades transformadoras de la misma» (Cortés, 2008: 26). Natalucci (2010) coincide en torno a la importancia de definir el rol del Estado en los movimientos sociales, y agrega la distinción entre lo que considera una estrategia autónoma y una heterónoma. Mientras que la primera estrategia está orientada a construir una propuesta independiente del Estado y su propósito es meramente cuestionarlo, la segunda buscaría generar una intervención con vistas a crear dispositivos que puedan institucionalizarse, pero sin por ello adherir a una doctrina política. Es decir, que estos dispositivos podrían "ratificar, instaurar o redefinir derechos» (Natalucci, 2010: 92). Tanto Natalucci como Cortés coinciden en que se trata de disputas simbólicas —esto torna importante el estudio de los productos culturales y, entre ellos, el teatroes decir, disputas por la representación que llevan consigo la delimitación de sentidos, luchas de poder e intereses materiales. En ese sentido, nos situamos en un grupo de teatro comunitario como Catalinas que, a nuestro entender, conoce esa tensión y la admite como parte ineludible del vínculo con el Estado.

Para enmarcar estas discusiones en nuestro tema de interés - las políticas culturales-, vemos que esa tensión con el poder estatal impregnó los distintos contextos políticos por los cuales pasó el grupo. Durante los primeros años del grupo, el gobierno Radical, bajo la presidencia de Raúl Alfonsín (1983-1989), impulsó una política de fomento y apertura con respecto a la cultura. Uno de los proyectos que surgió en este periodo fue el programa Cultural en Barrios, gestionado por la Secretaría de Cultura de la Ciudad de Buenos Aires en 1984. En un trabajo riguroso, Rosalía Winocur (1993) analiza la experiencia de este programa en la comunidad, identificando tres ausencias en él, que son interesantes para tener en cuenta en nuestro trabajo:

1. La ausencia de un diagnóstico que registre la herencia burocrática del Estado y la percepción de los sujetos sobre el Estado.

2. La suposición de que el impulso de circuitos alternativos de producción cultural y la descentralización de los servicios iban a garantizar por sí mismos una apropiación del capital cultural por parte de los sectores populares.

3. El apoyo en disciplinas artísticas como canales privilegiados de expresión de la cultura del pueblo, sin tener en cuenta las prácticas culturales, religiosas, comunitarias y recreativas.

4. La no consideración de las propias experiencias de organización y participación que establecen los sujetos en sus espacios cotidianos. En ese sentido, la participación que se da es de orden simbólico, porque se genera una ilusión de participación pero en realidad los vecinos no toman decisiones en lo relativo a la planificación, realización y evaluación de las políticas del programa. 
El trabajo de Winocur arroja luz sobre las problemáticas que impregnan los procesos de planificación y ejecución de las políticas públicas y que se observan con claridad en el caso de Catalinas Sur. Por un lado, el grupo de La Boca fue parte de este programa — que sigue aún vigente- desde 1986 y su experiencia se enmarca en un momento en donde la cultura se pensaba «desde arriba». Con esto remitimos a que, durante el gobierno Radical, el entusiasmo y las propuestas que surgían del Estado habilitaron la participación de las organizaciones comunitarias, pero sin considerar el factor territorial —en toda su dimensión física y simbólica - dentro de sus prácticas. Esto lo observamos en la reconstrucción que hicimos de aquel periodo según los testimonios de Bianchi: "A los radicales los llamábamos 'la patota cultural', tenían mucho ímpetu pero bajaban línea sin tener en cuenta la organización previa que existía en el lugar al cual iban». En el itinerario de experiencias, el director recuerda un proyecto llamado Un Tren de la Memoria, donde un grupo de jóvenes iban a los pueblos para hacer teatro y convocaban solo a los bomberos o a los curas. O en otra ocasión, una mujer apareció dando clases de teatro en la calle con cuatro o cinco alumnos, mientras que el grupo Catalinas tenía cerca de 80 vecinos-actores. En estos relatos observamos que las políticas culturales de los 80 se ven afectadas por dos de las ausencias marcadas por Winocur: por un lado, el desconocimiento de la idiosincrasia, la organización y las experiencias previas de los habitantes de la comunidad; por el otro, la idea de que la cultura debe «llevarse» a los pueblos, sin considerar las expresiones culturales propias ni los patrones de consumo, hábito y gusto de los sujetos.

El grupo Catalinas Sur se encuentra actualmente vinculado con el sector estatal a través de las siguientes instituciones, programas y acuerdos:

Instituciones Nacionales

- Fondo Nacional de las Artes. Subsidios y becas para todo tipo de desarrollo artístico.

- Instituto Nacional del Teatro. Subsidios para la realización de obras, mantenimiento de salas teatrales, giras, etcétera.

Instituciones Municipales

- Instituto para la Protección y Fomento de la Actividad Teatral no Oficial de la Ciudad (Proteatro). Dentro de los subsidios que otorga este instituto se encuentra la línea específica del teatro comunitario.

- Régimen de Promoción Cultural (Mecenazgo). A través de este programa se busca financiamiento en grandes empresas.

Internacionales

— Iberescena. Fondo de ayudas para las artes escénicas iberoamericanas.

Acuerdos

- Ministerio de Trabajo de la Nación.

- Ministerio de Acción Social.

- Cooperación española. 
Así como las políticas de algunos programas adolecen de una mirada que involucre la experiencia previa de la comunidad y sus antecedentes de organización, los subsidios que se otorgan a través de instituciones nacionales, provinciales o municipales construyen una lógica específica y expresan miradas determinadas sobre la cultura. Estos criterios podemos observarlos en las reglamentaciones, los tiempos de entrega o los requisitos que solicitan. En el caso de Proteatro y de Mecenazgo, los subsidios se gestionan a través de presentaciones que los grupos realizan cuando se abren las convocatorias. Estos serán luego evaluados por un jurado que decidirá cuáles serán los grupos beneficiados. En el caso de Mecenazgo, una vez que se habilita al grupo solicitante a participar del programa, es el mismo grupo el que debe ir en busca de las empresas para conseguir apoyo. Generalmente, los grupos que logran pertenecer a este programa son los de mayor trayectoria y reconocimiento, porque de esta forma las empresas garantizan más visibilidad de su responsabilidad empresarial. Incluye esta dinámica una lógica corporativa que, lejos de fomentar las expresiones culturales comunitarias en función de su capacidad de intervención social, apunta a jerarquizar aquellas de mayor recorrido, incorporando las empresas como agentes de financiamiento y desligando la responsabilidad estatal. El grupo Catalinas Sur se ha vinculado con numerosas empresas que han apoyado al grupo a lo largo de su trayectoria. Actualmente, cuentan, a través de Mecenazgo, con el aporte de Telefónica, Telecom, Banco Hipotecario, Banco Ithaú y las empresas Distribuidora Tresd SRL y Aramark-Central de Restaurantes SRL.

Otro elemento que encontramos en los procesos de gestión de estos subsidios es la necesidad de poseer competencia en materia de gestión, esto es, llenado de formularios, acopio y acceso a la documentación, lenguaje técnico, etcétera. En síntesis, será necesario para el grupo contar con personas que realicen tareas administrativas, que estén con disponibilidad horaria y posean las competencias pertinentes. En el caso del grupo Catalinas Sur, este posee una estructura propia en gestión de alrededor de 20 personas, que se encarga de la presentación de proyectos a los subsidios, las rendiciones y las documentaciones. La dimensión administrativa suele generar un problema en los grupos, y funciona como un filtro de acceso a los subsidios y programas.

Catalinas Sur tiene un gasto de 15.000 dólares mensuales, que se afrontan con los recursos de los programas estatales, pero también con el pago de las entradas y, además, en palabras del director, con la «autoexplotación». Otra de las claves del grupo está en la formación de recursos propios, es decir, la inversión de tiempo y dinero para que los integrantes del grupo adquieran los conocimientos necesarios para la organización. En este sentido, si se necesita aprender a gestionar recursos, se buscará la manera de que algunos miembros puedan adquirir esa competencia.

El vínculo con el Estado, tiene, además, otros ribetes que involucran estrategias de acercamiento con funcionarios y visibilización del proyecto: lo que Bianchi denomina como «actuar políticamente». Los modos de generar presión en la puja por recursos con el Estado dependerán de la empatía con ciertos funcionarios, de la coyuntura política que se esté viviendo y de la fortaleza 
del grupo que respalda ese proyecto. Un ejemplo de esto lo encontramos en la creación del programa nacional Puntos de Cultura, el cual, enmarcado en el programa de Cultura Viva Comunitaria, que nombramos anteriormente, propone acompañar los proyectos culturales creados por la comunidad. El impulso de este programa en Argentina se realizó gracias a la gestión de los miembros de la Red de Teatro en Comunidad y otras organizaciones como El Culebrón Timbal o Crear Vale la Pena, que promovieron la visita a la Argentina de Celio Turino, creador de Puntos de Cultura en Brasil, y a partir de allí comenzó a pensarse en la creación de la versión argentina de este programa, iniciado en el 2011.

Reconstruyendo las ideas fundamentales de este apartado, encontramos en el grupo Catalinas Sur a una organización artística comunitaria que interviene activamente en la vida cultural y política de la ciudad, que articula sus actividades con programas, subsidios y acuerdos con distintos estamentos del ámbito estatal. Tanto desde la concepción que el mismo director propone como desde la práctica, el Estado fue y es parte importante del desarrollo cotidiano del grupo. Si bien algunas de las fuentes de financiamiento que tiene el grupo son regulares (FNA, INT, Proteatro y Mecenazgo), no se trata de políticas de largo alcance que le permitan contar con recursos fijos, sino que demandan un trabajo constante de gestión administrativa que depende también de los avatares políticos. Los cambios de gestión, la rotación de funcionarios y los tiempos lentos en la concreción del financiamiento coadyuvan a la construcción de lazos débiles y problemáticos.

\subsection{Teatro Comunitario de Rivadavia}

El Teatro Comunitario de Rivadavia surgió en el año 2010 en el partido de Rivadavia, ubicado al noroeste de la provincia de Buenos Aires. Su conformación estuvo precedida por la del grupo de Teatro Popular de Sansinena, que se había formado en uno de los pueblos de ese mismo partido en el año 2006. La experiencia del teatro comunitario se extendió desde Sansinena hacia todo Rivadavia, y la constitución del grupo distrital incluyó, junto con el grupo de Sansinena, a otros cinco grupos, todos de pueblos rurales del mismo partido: González Moreno, San Mauricio, Roosevelt, Fortín Olavarría y América. La obra del grupo se llamó La historia se entreteje desde abajo y se cambia desde la comunidad, y participaron en ella aproximadamente 200 vecinos-actores. Consideramos que se trata de un caso paradigmático - tanto dentro de los estudios de teatro comunitario como de las ciencias sociales-, en donde una experiencia artística colectiva - el grupo de teatro- fue el puntapié para el surgimiento de la Cooperativa La Comunitaria, la cual se convirtió en un actor político de gran peso en la región, y portadora de una estructura organizativa inédita en el ámbito local.

En trabajos anteriores analizamos la potencialidad política del grupo (Fernández, 2015) y las operaciones de memoria en la construcción y la puesta en escena de su obra (Fernández, 2016). Allí pudimos dar cuenta del complejo 
vínculo que el grupo estableció con el Estado, y los modos a través de los cuales construyó su poder, de las diferencias entre el grupo de teatro y la Cooperativa como actores políticos. Nos interesa aquí recuperar estas reflexiones a la luz de la pregunta por el vínculo que adquiere el trinomio Estado, cultura y organizaciones comunitarias, específicamente en lo que respecta a los modos en que el grupo y su directora, María Emilia de la Iglesia, se vincularon y vinculan con el Estado. No sería objetivo de este trabajo enumerar pormenorizadamente las prácticas y acciones realizadas por el grupo, por lo tanto partiremos de ciertas consideraciones generales que, a nuestro entender, permiten encontrar notables diferencias de modos de organización y gestión con el grupo urbano trabajado, Catalinas Sur.

A lo largo de los años, los vínculos que el grupo de Rivadavia tejió con los sectores de poder, instituciones y comunidades locales distaron de ser homogéneos, y en cada nueva acción adquirieron matices diversificados. Por eso, las alianzas y contraalianzas suelen ser episódicas en un movimiento que hemos llamado «la dinámica del pacto discontinuo», que es un modo de vinculación que el grupo de Rivadavia instauró con el municipio a partir del estreno de la obra distrital, que plantea un vínculo que permanece en constante tensión, donde el grupo se alía en ciertas ocasiones con el municipio y en otras antagoniza. Es decir, que se presenta una discontinuidad de ese pacto, en función de los intereses del grupo y de las negociones que se lleven a cabo. Esta lógica está estructurada sobre cinco elementos: el fuerte liderazgo y personalismo de De la Iglesia; la autodeterminación sobre la propia acción, a la que hemos llamado «hacer ante todo»; la "novedad» de las actividades culturales que propone, en un lugar que está todo por hacerse; las apelaciones a las historias compartidas y al pasado común, sedimentadas y cristalizadas en recuerdos, historias, mitos, hábitos e idiosincrasia compartida, y el trabajo asociativo entre los vecinosactores.

En esa dinámica, el Estado, como actor social y político, está siempre presente en las operaciones de negociación o gestión, ya sea como apoyo económico o mediador entre el grupo y otras instituciones. Es importante destacar las formas en que se materializan las disputas políticas en el contexto de estas comunidades rurales para comprender la dimensión que adquiere la acción del grupo de Rivadavia y los proyectos de La Comunitaria sin caer en posturas facilistas que encasillen la propuesta dentro del rótulo de institucionalización y clausuren la potencialidad transformadora que los mismos aportan al ámbito social y político local. En ese sentido, lo enriquecedor es analizar las contradicciones y tensiones que el grupo de teatro y la Cooperativa generaron con el poder, y reflexionar sobre cómo construyen mecanismos de negociación y gestión, donde conviven instancias de tensión con momentos de consenso. Esto nos remite también al modo en que comprendemos al Estado dentro de esta dinámica, como actor partícipe ineludible del proceso de surgimiento y desarrollo del grupo de Rivadavia.

Encontramos que las acciones del grupo que - en sus inicios- se circunscribían al ámbito teatral, hoy se inscriben institucionalmente en el marco de 
la política local. En ese sentido, los repertorios de acción que se desplegaron a lo largo de los últimos seis años - y que hoy conviven - incluyen la práctica teatral, la toma y recuperación de espacios públicos, la campaña política y la disputa dentro de los ámbitos legislativos locales. En la trayectoria del grupo identificamos cuatro etapas: desarrollo y fortalecimiento (2009-2011); institucionalización (2011-2012); radicalización y diferenciación (2013-2014), y transición (de 2014 a la actualidad). Nos interesa, en esta recapitulación, dar cuenta de algunas cuestiones:

- En el año 2013, María Emilia de la Iglesia fue convocada por el entonces intendente de Rivadavia, Sergio Buil, como jefa de cultura del distrito. La directora asumió el cargo hasta abril de 2014, cuando fue desplazada del mismo por diferencias políticas.

- De la Iglesia es la representante de la Red Nacional de Teatro Comunitario frente al programa de Cultura Viva Comunitaria desde el año 2014.

Estas dos cuestiones nos remiten a pensar que el lazo del grupo de Rivadavia con el Estado y con otros actores del ámbito político es estrecho, fundamentalmente porque vemos que los representantes líderes del movimiento de teatro comunitario han participado directamente de espacios de construcción de legislaciones. En este caso, De la Iglesia buscó llevar adelante en su año de gestión el programa de Cultura Viva Comunitaria, a través de la difusión y el fortalecimiento de las capacidades creativas de los habitantes, independientemente de si estaban ligados a una disciplina artística o no. Con esta consigna, se planificaron actividades en los barrios, donde se convocó a toda la población a presentar sus trabajos plásticos, musicales o escénicos en las plazas y se armó un festival con pintadas de murales. Esto se replicó en cada pueblo y luego se realizó un festival general del partido en América, la ciudad capital. En mayo de 2013, De la Iglesia participó del Primer Congreso de Cultura Viva Comunitaria, que se llevó a cabo en la ciudad de La Paz (Bolivia), en calidad de funcionaria pública. Allí estrechó lazos con organizaciones sociales y culturales que trabajan desde el arte a partir de este programa, tanto en Argentina como en otros países de Latinoamérica como Bolivia, Perú, Brasil, El Salvador, Costa Rica, entre otros. A partir de ese encuentro, parte fundamental de su política involucró el establecimiento de nuevos vínculos a través de la organización de encuentros entre el grupo de teatro local y los de otros países.

Si analizamos los casos de Catalinas Sur y de Rivadavia se destacan algunas cuestiones referidas a los modos de construir poder, a los proyectos políticos que llevan a cabo, y, en última instancia, a la proyección futura de cada grupo.

- Las modalidades de construcción de poder de ambos grupos, en su vínculo con el Estado, dan cuenta de un diálogo fluido con figuras del ámbito político local. En el caso de Rivadavia, hay jerarquías marcadas del lugar de autoridad — con el intendente como máxima expresión del mismo- y los delegados de las instituciones como brazos extensivos de este. Esta modalidad 
de funcionamiento de la política local, que apunta a invisibilizar las jerarquías, está atravesada por una informalidad cargada de rituales, en donde es primordial acudir a la festividad o conmemoración de hechos significativos o personajes emblemáticos del pueblo para lograr la apelación a la identidad del lugar. Es decir, que las festividades adquieren significación como táctica de cohesión de los pobladores, ya que apelan a un pasado común que los identifica como portadores de esa singularidad identitaria (Fernández, 2012). Esta informalidad que señalamos promueve vínculos más cercanos e informales entre los directores de los grupos y las figuras de autoridad, pero a la vez puede generar instancias de tensión y disputa. Una diferencia notable entre los grupos radica en que, en el caso de Rivadavia, el teatro fue el germen para el surgimiento de la Cooperativa La Comunitaria, que se posicionó como antagonista del poder político local. A pesar de que existen lógicas distintas que estructuran al grupo de teatro y a la cooperativa, es innegable que el surgimiento de esta modificó la mirada y la percepción que el poder tenía sobre el grupo de teatro, sobre todo considerando que el núcleo duro de integrantes que sostiene cotidianamente ambas organizaciones (teatro y cooperativa) es el mismo.

En el caso de Catalinas Sur, en primer lugar, al hallarse en el ámbito urbano de la Ciudad de Buenos Aires, sede de los organismos nacionales más importantes en materia de financiación de la cultura, les permite acceder fácilmente al ámbito administrativo (oficinas, reglamentaciones, etcétera). Luego, el vínculo con los funcionarios ha mutado de acuerdo a las gestiones. Sin embargo, Bianchi admite que lo fundamental es que el funcionario interesado conozca de primera mano el proyecto y se vea personalmente involucrado, ya sea por vivir en el barrio o por ser espectador de las obras. Catalinas Sur, si bien posee iniciativas vinculadas al fomento del empleo o formación profesional, no se constituyó en una cooperativa al estilo de La Comunitaria, la cual se posiciona explícitamente como un espacio que disputa poder político en el ámbito instituyente ${ }^{13}$. En el caso del grupo de Rivadavia, se ha conseguido también apoyo de un diputado interesado en el proyecto, perteneciente al Frente para la Victoria ${ }^{14}$, que aportó un subsidio de 30.000 pesos para capacitaciones de los talleres de carpintería y herrería que brinda la Cooperativa La Comunitaria.

- El acceso a subsidios y la utilización de programas estatales son elementos fuertes en ambos grupos. Los años de trayectoria le permiten a Catalinas contar con un grupo de integrantes destinados específicamente a estas cuestiones, mientras que dentro de los miembros del grupo rivadaviano son muy pocos los integrantes que cuentan con los saberes necesarios para gestionar

13. A través de La Comunitaria se ha gestionado un proyecto de ordenanza para evitar la discriminación de las mujeres en la participación de las comisiones directivas de los clubes deportivos (tradicionalmente destinados a los hombres), y se han presentado proyectos para la creación de empleo y talleres de formación en varios de los pueblos del partido. Estas propuestas, ganadas a través del presupuesto participativo, han competido con las propuestas del municipio, y lograron la creación de talleres de carpintería, herrería, textiles y producción culinaria.

14. Coalición política argentina de orientación kirchnerista fundada en 2003. 
este tipo de subsidios, interpretar y concretar los pedidos administrativos. A pesar de ello, el Teatro Comunitario de Rivadavia ha contado, a lo largo de sus siete años, con financiamiento proveniente de varios organismos municipales, provinciales y nacionales, entre ellos, el municipio de Rivadavia - del cual recibió ayuda hasta el año 2014-, el Consejo Provincial de Teatro Independiente, el Fondo Nacional de las Artes, el Instituto Nacional del Teatro y el programa nacional de Puntos de Cultura. Estos subsidios fueron gestionados, en su mayoría, por la misma directora y por un grupo reducido de miembros del grupo. El vínculo del grupo con estos organismos se ha ido modificando a lo largo de los años, condicionado por la coyuntura específica de cada gestión política. En ese sentido, el municipio, que durante los primeros años fue un aliado del grupo, se convirtió en un antagonista a partir del año 2014, momento en que De la Iglesia fue alejada de su cargo de funcionaria. Respecto de las instituciones, actualmente el grupo encuentra dificultades para gestionar subsidios a través del Instituto Nacional del Teatro, por las trabas burocráticas y dificultades en el acceso a la información.

- El vínculo con la comunidad es uno de los elementos más importantes a la hora de pensar las estrategias de los grupos, tanto para autogestionarse como para elaborar modos de vinculación con los sectores de poder. Fundamentalmente, porque el modo de ejercer presión política que tienen los grupos está fuertemente ligado al apoyo de la organización comunitaria que hayan construido. Las características que reviste este vínculo en cada caso poseen un alto grado de especificación de acuerdo a los rasgos que tenga el territorio en el cual el grupo se establece. La diferencia urbano/rural se vuelve aquí una dimensión clave que nos permite considerar la existencia de distintas modalidades de vinculación con la comunidad. En ese sentido, la composición poblacional, los rasgos geográficos y las idiosincrasias configuran mapas que habilitan más o menos la posibilidad de crear lazos con la comunidad, a la vez que cada grupo establece objetivos diferenciados en relación con su proyecto político.

En un trabajo anterior ${ }^{15}$, reconstruimos los modos de gestión del Teatro Comunitario de Rivadavia que se desarrollaron en el Noveno Encuentro Nacional de Teatro Comunitario, el cual tuvo lugar en Rivadavia en el año 2011. Allí observamos que la estrategia del grupo no estuvo basada en los recursos obtenidos por los entes gubernamentales o los institutos de teatro, sino que se trató de confeccionar un mapa de colaboraciones a partir de los comerciantes y vecinos locales. Uno de los elementos más importantes en la organización fue el trabajo en red, sin el cual muchos de los pequeños pueblos no hubieran podido participar. Esto está en consonancia con una visión inclusiva e integradora de lo que debe ser una propuesta cultural, donde el eje se pone desde la comunidad, y no desde los círculos de poder. El apoyo de los

15. Se trata de un informe titulado «Nuevas estrategias colectivas de gestión teatral: el caso del grupo de Teatro de Rivadavia», elaborado para el Concurso Nacional de Proyectos de Investigación - Modelos de Gestión Teatral: Casos y Experiencias. Instituto Nacional de Teatro, año 2013. 
vecinos en este encuentro fue fundamental, y requirió de conocimientos en materia de gestión y negociación. La experiencia y la trayectoria previas son importantes a la hora de comprender a través de qué mecanismos los recursos que se consiguen adquieren mayor potencialidad, y pueden colaborar en la construcción de nuevos lazos con instituciones y comercios locales.

Las modalidades que cada grupo utiliza para vincularse con la comunidad son un rasgo que define en gran parte el tipo de proyecto que el grupo pretende construir. Si bien nuestro tema de estudio son las políticas culturales, muchos de los programas, subsidios y apoyos provenientes de estas políticas involucran a la comunidad, de manera diferenciada, y con distintos grados de participación. En esta perspectiva, el involucramiento de la comunidad con el proyecto del grupo permite generar una percepción de fortaleza y legitimidad, que es un bien preciado por las organizaciones para hacer valer sus pedidos frente a los entes gubernamentales.

\section{Reflexiones finales}

Sin intenciones de clausurar el debate, sino de abrirlo, retomaremos las ideas principales que surgieron en este escrito para habilitar nuevas preguntas que nos permitan entender el complejo vínculo del trinomio política, Estado y organizaciones comunitarias, a la luz de la experiencia del teatro comunitario.

En primer lugar, entendemos que la Red Nacional de Teatro Comunitario es de conformación heterogénea, y es justamente esa diversidad la que nos permite vislumbrar los modos diferenciados a través de los cuales cada grupo se vincula con el Estado, interviene en los procesos de planificación, gestión e implementación de las políticas culturales. Consideramos que los dos casos seleccionados constituyen ejemplos clarificadores ya que, en su complejidad y particularidad, nos muestran estructuras y dinámicas similares, en algunos casos, y muy dispares, en otros.

Una primera afirmación que quizá suene obvia, pero no por eso menos importante, es el lugar destacado que ha tenido el Estado en la trayectoria y el desarrollo de ambos grupos. Los dos han recurrido a los estamentos estatales con el fin de conseguir financiamiento, porque consideran que el Estado debe ser garante del derecho a la cultura, para todos los sectores de la sociedad. Ese derecho proviene de un discurso que se enmarca en una reciente tendencia de revalorización de la cultura como eje privilegiado de intervención para solucionar problemáticas de índole social, y de las cuales Argentina no está exenta. En los estudios teóricos referenciados en la primera parte de este trabajo, reconstruimos los paradigmas sobre los cuales se erigieron las políticas culturales de los últimos años. Allí observamos que si bien las instituciones y los apoyos a la cultura han sido prolíficos, en muy pocas ocasiones se delineó una planificación de las políticas culturales que posea un objetivo concreto de intervención en la comunidad a largo plazo. Quizá el caso más cercano fue el del programa Cultural en Barrios, aunque con las limitaciones antes señaladas. 
Si retomamos los casos de los grupos de teatro comunitario, ambas trayectorias nos permiten identificar una serie de elementos:

- Los grupos de teatro comunitario actúan políticamente. Son capaces de intervenir en ciertas dinámicas de la política local, nacional e internacional. En el caso de la Red Nacional de Teatro Comunitario, la actuación de Adhemar Bianchi, de Ricardo Talento - el fundador del Circuito Cultural Barracas-y de los referentes de Teatro en Comunidad impulsó la implementación del programa Puntos de Cultura en Argentina, al cual pertenecen muchos grupos de teatro comunitario, entre ellos el de Rivadavia. Además, encontramos referentes de los grupos - como De la Iglesia- que incursionan en cargos políticos en gestiones concretas. Fue por la actuación política de los referentes que se promulgó la Ley No 5227/14, de Promoción y Difusión del Teatro Comunitario, también se logró que se incorporara en los subsidios otorgados por el Proteatro la línea específica de teatro comunitario, lo que le permitió a los grupos contar con una legislación que los contemplara con sus particularidades, y no tener que adecuarse a otras líneas destinadas al teatro independiente.

En este punto, Bianchi destaca que a él le ofrecieron muchas veces puestos políticos, pero que eso desvirtuaría su trabajo. Por eso, el director recalca que hay que trabajar con el Estado pero no con partidos políticos particulares.

- Las trayectorias de militancia política son fundamentales para la construcción de liderazgos que permitan el desarrollo de los grupos. Según nuestras observaciones, se da en la dinámica de los grupos un movimiento donde un grupo muy reducido de integrantes se encarga de elaborar las estrategias políticas y gestionar los recursos. En su mayoría, estos integrantes del «núcleo duro» poseen figuras de liderazgo fuertes, enmarcadas en una historia de lucha o militancia, con conocimiento de lógicas políticas e interés en la construcción de un proyecto colectivo.

- Hay una tensión constante entre la actividad de gestión y la artística. En primer lugar, porque la gestión de recursos demanda tiempo y esfuerzo, que muchas veces se le quita a la actividad artística. El borramiento de la dimensión artística puede perjudicar profundamente a los grupos, ya que se trata de organizaciones cuya identidad se conformó a partir de la práctica artística, que es lo que los une y fortalece.

- Los programas y subsidios otorgados por las instituciones de la cultura son ayudas que colaboran en el desarrollo de la actividad, pero que simultáneamente generan filtros, muchas veces infranqueables para los grupos que no cuentan con trayectoria o que no poseen estructuras administrativas propias para gestionar esos recursos. La mayoría de estas ayudas están pensadas desde paradigmas culturales con una idea de mecenazgo o conservadurismo, ya que no se trata de políticas culturales de intervención, sino de ayudas económicas, muchas veces mediadas por las empresas y por intereses políticos. De todas maneras, es importante destacar que, a pesar de ello, ciertos programas, como el de Puntos de Cultura, permiten que muchas organiza- 
ciones artísticas comunitarias que no fueron tradicionalmente consideradas como «merecederas» del financiamiento público puedan finalmente acceder a recursos económicos públicos.

- Los mayores logros de la Red Nacional de Teatro Comunitario se dieron a través del trabajo en Red. Ya sea de la Red de Teatro en Comunidad como de la Red Nacional de Teatro Comunitario. Ambas redes han tenido un fuerte protagonismo en los movimientos recientes que se están dando en Latinoamérica en materia cultural. Tanto Cultura Viva Comunitaria como el Fondo Iberescena cuentan con presencia de varios grupos de teatro comunitario. De hecho, De la Iglesia es la representante de la Red de Teatro Comunitario en Cultura Viva.

- Las empresas, las fundaciones y las ONG son también actores de relevancia para las políticas culturales. Ya sea porque adquieren protagonismo específico en ciertas propuestas - como la de Mecenazgo- como porque fueron agentes clave en la conformación de los grupos fundadores. Fue gracias a la intervención de la Fundación Avina ${ }^{16}$ que los grupos de Catalinas Sur y el Circuito Cultural Barracas se encontraron con otras organizaciones argentinas, como Crear Vale la Pena y El Culebrón Timbal, y también con la Corporación Teatral Nuestra Gente y Esquina Latina -Colombia-, Pompas Urbanas —Brasil—, Arenas y Esteras y Vichama Teatro —Perú—, entre otros, y conformaron la Red de Teatro en Comunidad.

En función de lo dicho hasta aquí, podemos afirmar que las políticas culturales son un campo de estudios fecundo para reflexionar en torno a las complejidades que rodean las decisiones en materia de cultura, las implicancias simbólicas y materiales de dichas decisiones, y la relevancia que adquieren las organizaciones de la sociedad civil dentro de ese mapa. El teatro comunitario ha sido un lente desde el cual mirar estos procesos, de cara a la búsqueda de nuevos interrogantes que den un paso más en la comprensión de esa complejidad. Los juegos, intercambios y disputas que se desarrollan entre el Estado y estos grupos dan cuenta de la necesidad de seguir ahondando en la identificación de las problemáticas que los atraviesan, la búsqueda de estrategias y nuevos caminos que permitan sortear las burocracias, para poder potenciar el desarrollo cultural y la «justicia cultural» más allá de la obtención de subsidios o el otorgamiento de ayudas económicas.

El campo de acción que genera el teatro comunitario, como espacio de expresión, disputa, negociación y lucha, se extiende desde un ejercicio ciudadano estructurado en dimensiones simbólicas — como la práctica reflexiva en la construcción de la obra, el intercambio de experiencias y socializaciónhasta prácticas que lentamente se insertan en ámbitos concretamente políticos, que permiten incidir en pequeñas transformaciones legislativas y normativas

16. La Fundación Avina comenzó sus primeras acciones en 1994, lideradas por su fundador, el empresario suizo Stephan Schmidheiny. Hace más de 20 años la fundación invierte en proyectos a gran escala (http://www.avina.net/). 
que amplían el espectro de acción de estos grupos, democratizando el acceso a la cultura. A pesar de estas potencialidades, el margen de acción de estos grupos es limitado en ciertos ámbitos, ya que se trata de organizaciones artísticas que desde sus principios constitutivos se oponen a la práctica política partidaria excluyente, y actúan de manera estratégica, dinámica, múltiple, a través de distintos canales de la estructura estatal, y dibujando un recorrido que adquiere sus propios ritmos y lógicas, por fuera de los circuitos tradicionales de la política. Esto no quiere decir que los grupos no se inmiscuyen en estos, sino que buscan generar, a partir de sus propias dinámicas de construcción de poder, vínculos estratégicos y coyunturales que se adapten a las demandas que van surgiendo cotidianamente.

Lo dicho hasta aquí abre el panorama dentro de los estudios sociales del arte hacia problemáticas escasamente exploradas, donde el arte, la política, la ciudadanía y el Estado son líneas de fuga que necesitan ser profundamente analizadas en función de casos concretos, con el fin de generar reflexiones que evidencien la centralidad de la cultura como espacio de disputa política, de lucha por los derechos e intervención concreta, tanto sobre marcos normativos como en políticas y acciones específicas.

\section{Referencias bibliográficas}

BARBOSA Lima, Luciana (2014). «As políticas culturais como espaço de intervenção crítica dos estudos culturais». En: GrimsOn, A. Culturas politicas y políticas culturales. Fundación de Altos Estudios Sociales. CABA: Ediciones Böll Cono Sur.

BAYARDO, R. (2002). Sobre el financiamiento público de la cultura. Politicas culturales y economía cultural. Ponencia en el III Congreso Virtual de Antropología. Equipo Naya. $<$ http://www.equiponaya.com.ar/congreso2002/ponencias/rubens_bayardo.htm>.

- (2005a). «Políticas culturales y cultura política». Argumentos, Revista de Crítica Social, 5. Buenos Aires.

$<$ http://publicaciones.sociales.uba.ar/index.php/argumentos/article/view/841>.

- (2005b). La cuestión de los consumos culturales en Argentina: el impacto de las políticas culturales y de la crisis del Estado. ALAS. Porto Alegre.

- (2008a). «Políticas culturales: derroteros y perspectivas contemporáneas». RIPS. Revista de Investigaciones Politicas y Sociológicas, 7 (1), 17-29. $<$ http://www.redalyc.org/pdf/380/38070103.pdf>.

- (2008b). ¿Hacia dónde van las políticas públicas culturales? $1^{\circ}$ Simposio Internacional de Políticas Públicas Culturales en Iberoamérica. Facultad de Ciencias Económicas, Universidad Nacional de Córdoba. <www.culturafce.unc.edu.ar>.

BIDEGAIN, Marcela (2007). Teatro comunitario: arte y transformación social. Buenos Aires: Atuel.

Bonfil BatalLa, Guillermo (2002). Culturas populares y politica cultural. México: Conaculta.

BRUNNER, J. (1987). Ciencias sociales y el tema de la cultura: notas para una agenda de investigación. Documento de Trabajo ${ }^{\circ}$ 332. Santiago de Chile: FLACSO. $<$ http://flacsochile.org/biblioteca/pub/memoria/1987/000270.pdfs.

CAMAROTTI, Renata (2014). « ¿Cultura para el desarrollo? Cruces entre 'lo social' y 'lo cultural' en las políticas públicas de cultura». En: Grimson, Alejandro (Comp.). 
Culturas Políticas y Políticas Culturales. Ciudad Autónoma de Buenos Aires. Fundación Altos Estudios Sociales, 163-172.

<http://biblioteca.clacso.edu.ar/clacso/se/20140617035730/culturas.pdf>.

CORTÉS, Martín (2008). Movimientos sociales y Estado en Argentina: entre la autonomía y la institucionalidad. Informe final del concurso: Gobiernos progresistas en la era neoliberal: estructuras de poder y concepciones sobre el desarrollo de América Latina y el Caribe. Programa Regional de Becas Clacso. <http://bibliotecavirtual.clacso.org.ar/ar/libros/becas/2008/gobpro/cortes.pdf>.

Crespo Oviedo, Luis Felipe (2003). «Políticas culturales: viejas tareas, nuevos paradigmas». Derecho y Cultura, 9, 23-42. <http://www.paginaspersonales.unam.mx/ files/231/POLITICAS_CULTURALES_(DERECHO_CULTURA).pdf>.

Escobar, Arturo; Álvarez, Sonia y Dagnino, Evelina (2001). Política cultural y cultura politica. Una nueva mirada sobre los movimientos sociales latinoamericanos. Madrid: Taurus e ICANH.

EsteBAn, M. L. (2013). Hacia donde van las organizaciones comunitarias, sus proyectos y su impacto en el desarrollo local. Chaco: Ponencia Congreso Argentino de Cultura.

FERNÁNDEZ, Clarisa (2012). Recuerdos, espejos y memorias en el teatro comunitario argentino contemporáneo. Memoria colectiva, identidades y espacio público en las prácticas del Grupo de Teatro Popular de Sansinena. Tesis de Maestría en Ciencias Sociales. Facultad de Humanidades y Ciencias de la Educación de la UNLP. <http://www.memoria.fahce.unlp.edu.ar/library?a=d\&c=tesis\&d=Jte739>.

- (2013). «Prácticas culturales y conciencia histórica. Reflexiones sobre la construcción y reapropiación de la historia a través del prisma del teatro comunitario». Páginas. Revista Digital de la Escuela de Historia, 5 (8), 97-117. <http://hdl.handle.net/2133/4695>.

- (2015). La potencia en la escena. Teatro Comunitario de Rivadavia: historicidad, politica y sujetos en juego/s. Tesis de Doctorado en Ciencias Sociales. Facultad de Humanidades y Ciencias de la Educación de la UNLP. $<$ http://www.memoria.fahce.unlp.edu.ar/library?a=d\&c=tesis\&d=Jte1170>.

- (2016). «Teatro Comunitario de Rivadavia. La dramaturgia como constructo identitario». Revista Argus-a, VI (22).

$<$ http://www.argus-a.com.ar/archivos-dinamicas/teatro-comunitario-de-rivadavia.pdfs.

FERREÑO, Laura (2014). «En nombre de los otros. Ciudadanía y políticas culturales». Culturas políticas y políticas culturales. GRIMSON, Alejandro (comp.). Fundación de Altos Estudios Sociales, 109-116. CABA: Ediciones Böll Cono Sur.

García Canclini, N. (1987). Políticas culturales en América Latina. México: Grijalbo.

GARretón, Manuel (2008). «El espacio cultural latinoamericano revisitado». En: Rubim, L. y Miranda, N. Transversalidades da cultura. Salvador - Bahia: Edufba Universidade Federal Da Bahia.

Grimson, Alejandro (2014). «Políticas para la justicia social». En: Grimson, Alejandro (comp.). Culturas políticas y políticas culturales. Fundación de Altos Estudios Sociales. Ciudad Autónoma de Buenos Aires: Ediciones Böll Cono Sur.

INFANTINO, Julieta (2008). «El arte como herramienta de intervención social entre jóvenes en la Ciudad de Buenos Aires. La experiencia de "Circo Social del Sur"». Revista Medio Ambiente y Urbanización, 69, 35-54.

$<$ https://revistas.unc.edu.ar/index.php/antropologia/article/view/11468>.

LimA, Santiago (2010). «Políticas culturales en la Argentina: mecenazgo y rol del Estado». Revista Telón de Fondo, 11, 1-12.

<http://www.telondefondo.org/numeros-anteriores/numero11/articulo/267/ politicas-culturales-en-la-argentina-mecenazgo-y-rol-del-estado.html>. 
LOGIÓDICE, María Julia (2012). «Políticas culturales, la conformación de un campo disciplinar. Sentidos y prácticas en las opciones de políticas». Revista Documentos y aportes en Administración pública y gestión estatal, 18 (12). <https://doi.org/10.14409/da.v1i18.1279>

LÓPEZ BORBÓn, Liliana (2001). Políticas culturales orientadas al plano de la vida cotidiana: evaluación de las estrategias de comunicación del Programa de Cultura Ciudadana (Bogotá 1995-1997). Argentina: CLACSO.

<http://bibliotecavirtual.clacso.org.ar/ar/libros/becas/2000/lopez.pdf>.

MACCIONI, L. (2002). «Valoración de la democracia y resignificación de 'política' y 'cultura': Sobre las políticas culturales como metapolíticas». En: MATO, D. (coord.). Estudios y otras prácticas intelectuales latinoamericanas en cultura y poder, 189-200. Caracas, Venezuela: CLACSO, Consejo Latinoamericano de Ciencias Sociales.

Marradi, A; Archenti, N. y Piovani, J.I. (2007). Metodología de las ciencias sociales. Buenos Aires: Emecé.

Margulis, M.; URResti, M. y LeWIN, H. (2014). Intervenir en la cultura: más allá de las politicas culturales. Buenos Aires: Biblios.

MARTín ZamoranO, M. (2016). "La transformación de las políticas culturales en Argentina durante la primera década kirchnerista: entre la hegemonía y la diversidad». Aposta. Revista de Ciencias Sociales, 70, 53-83.

$<$ http://apostadigital.com/revistav3/hemeroteca/zamorano1.pdf>.

MATO, D. (2002). Estudios y otras prácticas intelectuales latinoamericanas en cultura y poder. Caracas, Venezuela: CLACSO, Consejo Latinoamericano de Ciencias Sociales.

Mejía Arango, J. (2009). "Apuntes sobre las políticas culturales en América Latina, 1987-2009». Colombia Pensamiento Iberoamericano: Revista de Economía Política. Ed. v. N/A, fasc. 4, 2a época , 105-130. Universidad EAFIT. Medellín.

Moulin, R. (1986). «El mercado y el museo. La constitución de los valores artísticos contemporáneos». Revue Française de Sociologie, XXVII, 369-395.

NatAluCci, Ana (2010). "Aportes para la discusión sobre la autonomía o heteronomía de las organizaciones sociales. La experiencia del Movimiento Barrios de Pie, 2002-2008». Revista Laboratorio, sobre el Cambio Estructural y la Desigualdad Social. Año XI, n 23.

<http://publicaciones.sociales.uba.ar/index.php/lavboratorio/article/view/100>.

Nivón Bolán, Eduardo (2004). "Malestar en la cultura. Conflictos en la política cultural mexicana reciente». Pensar Iberoamérica, Revista de Cultura, 7. <http://www.oei.es/historico/pensariberoamerica/ric07a01.htm>.

- (2006). Políticas culturales en México: 2006-2020. Hacia un plan estratégico de desarrollo cultural, México: Universidad de Guadalajada - Miguel Ángel Porrúa.

- (2011). «As políticas culturais e os novos desafios. O patrimônio imaterial na estruturação das novas políticas culturais». En: CALABre, Lía (organizadora). Politicas Culturais, teoría e praxis. Itaú Cultural. Rio de Janeiro: Fundação Casa de Rui Barbosa.

Ochoa Gautier, A. M. (2002). «Políticas culturales, academia y sociedad». En: MATO, D. (coord.). Estudios y otras prácticas intelectuales latinoamericanas en cultura y poder, 213-224. Caracas: Consejo Latinoamericano de Ciencias Sociales (CLACSO) y CEAP, FACES, Universidad Central de Venezuela.

Orozco, José Luis (2007). «Políticas culturales y modelos de gestión cultural». En Orozco, J. L. (comp). Politicas culturales. Una revisión desde la gestión cultural. Universidad de Guadalajara. México: Sistema de Universidad Virtual. 
OszlaK, Oscar y O’Donnell, Guillermo (2007). «Estado y políticas estatales en América Latina: hacia una estrategia de investigación». Lecturas sobre el Estado y las políticas públicas. Retomando el debate de ayer para fortalecer el actual. Proyecto de modernización del Estado. Jefatura de Gabinete de Ministros de la Nación. Buenos Aires.

PAllini, Verónica (2008). El rol del Estado en las políticas culturales. Grupo Naya. <http://www.equiponaya.com.ar/articulos/politica05.htm>.

PORTO, Marta (2004). «Recuperar a dimensão politica da cultura: nosso principal desafio». Pensar Iberoamérica, Revista de Cultura, 7. <http://www.oei.es/historico/pensariberoamerica/ric07a03.htm>.

ProAÑo Gómez, Lola (2007). Poéticas de la globalización en el teatro latinoamericano. Universidad de California, Irvine: Colecciones Gestos.

- (2013). Teatro y estética comunitaria. Miradas desde la filosofía y la política. Buenos Aires: Biblos.

RAGGIO, Liliana (1997). El enfoque antropológico en el estudio de las políticas sociales. Posibilidades y limitaciones. Ponencia V CAAS. Publicada en NAyA.

Rubim, A. (2006). Actores sociales, redes y politicas culturales. Universidad Federal de Bahía, Brasil. CAB Cátedras de Integración Convenio Andrés Bello 2, Edición del Convenio Andrés Bello.

TOVAR y DE TERESA, Rafael (1994). Modernización y política cultural. México: FCE.

WinOCUR, Rosalía (1993). «Políticas culturales y participación popular en Argentina: la experiencia del programa Cultural en Barrios (1984-1989)». Perfiles Latinoamericanos, Revista de la Facultad Latinoamericana de Ciencias Sociales, 2 (3), 97-118. <http://www.redalyc.org/articulo.oa?id=11500306>.

Wortman, A. (2002). "Vaivenes del campo intelectual político cultural en la Argentina». En: MATO, D. (coord.). Estudios y otras prácticas intelectuales latinoamericanas en cultura y poder. 327-338. Caracas: Consejo Latinoamericano de Ciencias Sociales (CLACSO) y CEAP, FACES, Universidad Central de Venezuela.

- (2005). «El desafío de las políticas culturales en Argentina». En: MATO, Daniel (comp). Cultura, politica y sociedad. Perspectivas latinoamericanas. CLACSO, Buenos Aires. Disponible en: <http://www.clacso.org.ar/clacso/novedades_editoriales/libros_clacso/ buscar_libro_detalle.php?id_libro=162\&campo=autor\&texto=wortman>

Yúdice, G. (2002). "Contrapunteo estadounidense/latinoamericano de los estudios culturales». En: MATO, D. (coord.). Estudios y otras prácticas intelectuales latinoamericanas en cultura y poder. 339-362. Caracas: CLACSO, Consejo Latinoamericano de Ciencias Sociales. 